\title{
HUBUNGAN TINGKAT STRESS DENGAN KADAR GULA DARAH PADA PASIEN DIABETES MELITUS DI POLI PENYAKIT DALAM RUMAH SAKIT BHAYANGKARA PALEMBANG TAHUN 2019
}

\author{
Sri Mulia Sari ${ }^{1}$, Hersianda ${ }^{2}$ \\ 1. Dosen Tetap STIK Siti Khadijah Palembang \\ srimulia_s@yahoo.com
}

\begin{abstract}
ABSTRAK
Diabetes Melitus merupakan penyakit gangguan metabolisme kronis yang ditandai peningkatan glukosa darah (hiperglikemi), yang disebabkan karena ketidakseimbangan antara suplai dan kebutuhan untuk memfasilitasi masuknya glukosa dalam sel yang dapat di gunakan untuk metabolisme dan pertumbuhan sel. Bila seseorang mengalami stress maka respon terhadap stress dapat meningkatkan kadar hormon adrenalin yang mengubah cadangan glikogen menjadi glukosa dalam hati. Kadar glukosa yang terjadi secara terus menerus dapat menyebabkan komplikasi yang dapat memperberat penyakit pasien. Tujuan penelitian ini adalah untuk mengetahui hubungan tingkat stress dengan kadar gula darah pada pasien Diabetes Melitus di Poli Penyakit Dalam Rumah Sakit Bhayangkara Palembang Tahun 2019. Penelitian ini menggunakan desain penelitian kuantitatif dengan menggunakan metode survey analitik melalui pendekatan desain cross sectional. Penelitian ini dilakukan pada bulan Juni s.d. Agustus 2019 di Poli Penyakit Dalam Rumah Sakit Bhayangkara dengan teknik pengambilan sampel menggunakan accidental sampling berjumlah 85 responden. Dari hasil uji statistik dengan menggunakan yaitu chi-square, didapatkan $p$ value $=0,034<0,05$, yang artinya ada hubungan tingkat stress dengan kadar gula darah pada pasien Diabetes Melitus di Poli Penyakit Dalam Rumah Sakit Bhayangkara Palembang Tahun 2019. Dari hasil peneliian ini diharapkan agar petugas kesehatan dapat memberikan pendidikan kesehatan kepada pasien Diabetes Melitus agar mengurangi stress, supaya kadar gula darahnya dapat terkontrol sehingga dapat meminimalisir terjadinya komplikasi.
\end{abstract}

Kata Kunci : Tingkat Stress, Kadar Gula, Diabetes Melitus 


\section{PENDAHULUAN}

Pada era globalisasi saat ini telah terjadi transisi epidemiologi yaitu berubahnya pola penyebaran penyakit dari penyakit menular menjadi penyakit tidak menular, hal ini dikarenakan pola hidup masyarakat yang tidak sehat mulai dari pola konsumsi yang serba instan, semakin canggihnya teknologi yang menyebabkan seseorang kurang bergerak atau melakukan aktivitas fisik, life style, dan lain-lain, salah satu penyakit tidak menular yang banyak ditemukan di masyarakat yaitu diabetes melitus (DM) atau biasa juga disebut penyakit gula atau kencing manis (Waspadji dkk, 2013).

Diabetes Melitus merupakan penyakit gangguan metabolisme kronis yang ditandai peningkatan glukosa darah (hiperglikemi), disebabkan karena ketidakseimbangan antara suplai dan kebutuhan untuk memfasilitasi masuknya glukosa dalam sel agar dapat di gunakan untuk metabolisme dan pertumbuhan sel. Berkurang atau tidak adanya insulin menjadikan glukosa tertahan didalam darah dan menimbulkan peningkatan gula darah, sementara sel menjadi kekurangan glukosa yang sangat di butuhkan dalam kelangsungan dan fungsi sel (Nirmala, 2015).

Pasien Diabetes harus tergantung pada terapi pengelolaan diabetes. Hal tersebut dapat menimbulkan permasalahan misalnya pasien merasa lemah kerena harus membatasi diet, setiap perubahan dalam kesehatan dapat menjadi stressor. Keharusan pasien Diabetes Melitus mengubah pola hidupnya agar gula darah dalam tubuh tetap seimbang dan apabila tidak seimbang dapat mengakibatkan mereka rentan terhadap stress, karena stress akan terjadi apabila seseorang merasakan adanya ketidaksesuaian antara sumber daya yang dimiliki dengan tuntutan situasi yang harus dijalankan ketika tuntutan situasi dirasakan berbeda dangan situasi sebelumnya dan terlalu berat maka stres akan terjadi (Nirmala, 2015).

Bila seseorang mengalami stress maka respon terhadap stress dapat meningkatkan kadar hormon adrenalin yang mengubah cadangan glikogen menjadi glukosa dalam hati. Kadar glukosa yang terjadi secara terus menerus dapat menyebabkan komplikasi pada penderita diabetes melitus antara lain komplikasi diabetes akut dan komplikasi diabetes kronis (Jamaluddin, 2012).

Menurut hasil penelitian Derek dkk (2017) menyatakan bahwa terdapat hubungan tingkat stress dengan kadar gula darah pada pasien diabetes melitus dengan dengan nilai $p$-value sebesar 0,000 .

Menurut hasil penelitian Izzati dkk (2015) menyatakan bahwa terdapat hubungan tingkat stress dengan kadar gula darah pada pasien diabetes melitus dengan nilai $p$-value sebesar 0,017 .

Menurut data World Health Organization, menjelaskan bahwa penyakit Diabetes Mellitus dapat diperkirakan akan terus bertambah dari tahun hingga 415 juta orang di seluruh dunia yang mengidap penyakit diabetes melitus ( WHO 2016 ).

Menurut hasil Riskesdas bahwa Diabetes Melitus dari tahun 2013-2018 di dapatkan pada tahun 2013 berjumlah 6,9\% dan pada tahun 2018 berjumlah 8,5\% (Riskesdas, 2018), sedangkan di Provinsi Sumatra Selatan, tercatat dari tahun 2016-2017 mengalami peningkatan. Pada tahun 2016 sebesar 45\% dan pada tahun 2017 sebesar 55\% (Dinkes Prov Sumsel, 2017).

Menurut data Dinas Kota Palembang jumlah penderita Diabetes Mellitus Pada tahun 2017 sebanyak 33.676 kasus penderita Diabetes Melitus dan pada tahun 2018 sebanyak 49.432 kasus Diabetes Mellitus (Dinkes Kota Palembang, 2018). 
Berdasarkan data rekam medik yang di dapat peneliti di Rumah Sakit Bhayangkara Palembang pasien Diabetes Mellitus pada tahun 2016 sebanyak 2.899 orang, tahun 2017 sebanyak 6.974 orang, tahun 2018 sebanyak 4.392 orang dan pada tahun 2019 antara bulan Januari-Maret sebanyak 552 orang.

Berdasarkan studi pendahuluan yang dilakukan oleh peneliti, terhadap 5 (lima) responden pada pasien Diabetes Mellitus di Rumah Sakit Bhayangkara Palembang ternyata 3 (tiga) responden yang masih mengalami peningkatan kadar gula darah yang disebabkan oleh stress.

Berdasarkan uraian diatas peneliti tertarik untuk meneliti tentang Hubungan Tingkat Stress dengan Kadar Gula Darah pada Pasien Diabetes Melitus di Poli Penyakit Dalam Rumah Sakit Bhayangkara Palembang Tahun 2019.

\section{METODE PENELITIAN}

Penelitian ini menggunakan desain penelitian kuantitatif dengan menggunakan metode survey analitik melalui pendekatan desain cross sectional. Teknik pengambilan sampel menggunakan accidental sampling berjumlah 85 responden yang dilakukan pada bulan Juni s.d. Agustus 2019 di Poli Penyakit Dalam Rumah Sakit Bhayangkara Palembang Tahun 2019.

\section{HASIL DAN PEMBAHASAN}

\section{HASIL PENELITIAN}

Analisis Univariat

Tabel 1

Distribusi Frekuensi Responden Berdasarkan Kadar Gula Darah pada Pasien Diabetes Melitus di Poli Penyakit Dalam Rumah Sakit Bhayangkara Palembang Tahun 2019

\begin{tabular}{cccc}
\hline No & $\begin{array}{c}\text { Kadar Gula } \\
\text { Darah }\end{array}$ & $\begin{array}{c}\text { Frekuensi } \\
(\mathrm{n})\end{array}$ & $\begin{array}{c}\text { Persentase } \\
(\%)\end{array}$ \\
\hline 1 & Terkontrol & 40 & 47,1 \\
2 & Tidak & 45 & 52,9 \\
& $\begin{array}{c}\text { terkontrol } \\
\text { Jumlah }\end{array}$ & 85 & 100 \\
\hline
\end{tabular}

Berdasarkan Tabel.1 diatas, didapatkan bahwa dari 85 responden menunjukkan kadar gula darah terkontrol sebanyak 40 responden $(47,1 \%)$ lebih banyak dibandingkan dengan responden dengan kadar gula darah tidak terkontol sebanyak 45 responden $(52,9 \%)$.

Tabel 2

Distribusi Frekuensi Responden Berdasarkan Tingkat Stress pada Pasien Diabetes Melitus di Poli Penyakit Dalam Rumah Sakit Bhayangkara Palembang Tahun 2019

\begin{tabular}{cccc}
\hline No & $\begin{array}{c}\text { Tingkat } \\
\text { Stres }\end{array}$ & $\begin{array}{c}\text { Frekuensi } \\
(\mathbf{n})\end{array}$ & $\begin{array}{c}\text { Presentase } \\
(\mathbf{\%})\end{array}$ \\
\hline 1 & Stress & 43 & 50,6 \\
& Ringan & & \\
2 & Stress & 38 & 44,7 \\
& Sedang & & \\
3 & Stress Berat & 4 & 4,7 \\
& Jumlah & 85 & 100 \\
\hline
\end{tabular}

Berdasarkan Tabel 2 diatas, didapatkan bahwa dari 85 responden menunjukkan tingkat stress pada pasien Diabetes Melitus yang stres ringan sebanyak 43 responden $(50,6 \%)$ lebih banyak dibandingkan dengan responden yang stres sedang sebanyak 38 responden $(44,7 \%)$ dan stres berat sebanyak 4 responden $(4,7 \%)$.

\section{Analisis Bivariat}

Tabel 3

Hubungan Tingkat Stress dengan Kadar Gula Darah pada Pasien Diabetes Melitus di Poli Penyakit Dalam Rumah Sakit Bhayangkara Palembang Tahun 2019.

\begin{tabular}{|c|c|c|c|c|c|c|c|c|}
\hline \multirow{3}{*}{$\begin{array}{l}\mathrm{N} \\
\mathrm{o}\end{array}$} & \multirow{3}{*}{$\begin{array}{l}\text { Tingkat } \\
\text { Stress }\end{array}$} & \multicolumn{4}{|c|}{ Kadar Gula Darah } & \multirow{2}{*}{\multicolumn{2}{|c|}{ Jumlah }} & $P$ \\
\hline & & \multicolumn{2}{|c|}{ Terkontrol } & \multicolumn{2}{|c|}{$\begin{array}{c}\text { Tidak } \\
\text { terkontrol }\end{array}$} & & & $\begin{array}{l}\text { Va } \\
\text { lue }\end{array}$ \\
\hline & & $\mathrm{n}$ & $\%$ & $\mathrm{n}$ & $\%$ & $\mathrm{n}$ & $\%$ & \\
\hline 1 & $\begin{array}{c}\text { Stress } \\
\text { Ringan } \\
\end{array}$ & 26 & 60,5 & 17 & $\begin{array}{c}39, \\
5\end{array}$ & 43 & $\begin{array}{c}10 \\
0 \\
\end{array}$ & 0,0 \\
\hline 2 & $\begin{array}{c}\text { Stress } \\
\text { Sedang }\end{array}$ & 12 & 31,6 & 26 & $\begin{array}{c}68, \\
4\end{array}$ & 38 & $\begin{array}{c}10 \\
0\end{array}$ & 34 \\
\hline 3 & $\begin{array}{l}\text { Stress } \\
\text { Berat } \\
\end{array}$ & 2 & 50 & 2 & 50 & 4 & $\begin{array}{c}10 \\
0 \\
\end{array}$ & \\
\hline & Jumlah & 85 & 47,1 & 45 & $\begin{array}{c}52, \\
9\end{array}$ & 85 & $\begin{array}{c}10 \\
0\end{array}$ & \\
\hline
\end{tabular}


Dari Tabel 3 Didapatkan dari 38 responden yang memiliki tingkat stress sedang yang kadar gula darahnya tidak terkontrol sebanyak 26 responden $(68,4 \%)$ lebih banyak dibandingkan dari dari 4 responden yang stress berat yang kadar gula darah tidak terkontrol sebanyak 2 responden (50\%) dan 43 responden yang tingkat stress ringan yang kadar gula darah tidak terkontrol sebanyak 17 responden (39,5\%), didapatkan $\rho$ value $=0,034<0,05$, berarti ada hubungan tingkat stres dengan kadar gula darah pada pasien Diabetes Melitus, sehingga hipotesis yang mengatakan bahwa ada hubungan tingkat stress dengan kadar gula darah pada pasien Diabetes Melitus di Poli Penyakit Dalam Rumah Sakit Bhayangkara Palembang Tahun 2019.

\section{Pembahasan}

\section{Analisis Univariat}

\section{a. Kadar Gula Darah pada Pasien Diabetes Melitus}

Hasil penelitian yang dilakukan di Poli Penyakit Dalam Rumah Sakit Bhayangkara Palembang didapatkan bahwa kadar gula darah pasien Diabetes Melitus terkontrol 40 responden $(47,1 \%)$ lebih sedikit dari kadar gula darah tidak terkontrol sebanyak 45 responden $(52,9 \%)$.

Kadar gula darah merupakan sejumlah glukosa yang terdapat di plasma darah (Dorland, 2013). Kadar gula darah sebagian besar dikarenakan beberapa faktor yaitu stres, pola makan yang tidak teratur (diet), lupa minum obat dan kurangnya berolahraga (Adam, 2019).

Penelitian ini sejalan dengan penelitian yang dilakukan Bedjo (2014) di STIKes Nu Tuban didapatkan bahwa kadar gula darah pasien Diabetes Melitus terkontrol 16 responden $(44,4 \%)$ lebih sedikit kadar gula darah tidak terkontrol sebanyak 20 responden $(55,6 \%)$.

Dari hasil penelitian, teori dan penelitian terkait yang didapat maka peneliti berasumsi bahwa banyaknya penderita diabetes melitus yang memiliki kadar gula darah terkontrol menunjukkan bahwa penatalaksanaan dipengaruhi banyak faktor antara lain : diet, aktivitas fisik, stress dan umur. Selama melakukan aktivitas terjadi peningkatan penggunaan glukosa dan glikogen otot, sehingga kadar gula darah akan berkurang karena glukosa akan dibakar menjadi energi saat beraktivitas.

\section{b. Tingkat Stress pada Pasien Diabetes Melitus}

Hasil penelitian yang dilakukan di Poli Penyakit Dalam Rumah Sakit Bhayangkara Palembang didapatkan bahwa tingkat stress ringan sebanyak 43 responden $(50,6 \%)$, tingkat stress sedang sebanyak 38 responden $(44,7 \%)$ dan tingkat stress berat sebanyak 4 responden $(4,7)$ dari 85 responden.

Stress adalah respon tubuh yang tidak spesifik terhadap setiap kebutuhan yang terganggu, suatu fenomena universal yang terjadi dalam kehidupan sehari-hari dan tidak dapat dihindari, setiap orang mengalaminya, stress memberi dampak secara total pada individu yaitu terhadap fisik, psikologis, intelektual, sosial dan spiritual, stres dapat mengancam kesimbangan fisiologis (Meivy dkk, 2017)

Penelitian ini sejalan dengan Bedjo (2014) yang dilakukan di STIKes $\mathrm{Nu}$ Tuban yang didapatkan tingkat stress ringan sebanyak 17 (47,2\%), stress sedang sebanyak 10 responden $(27,7 \%)$ dan tingkat stress berat sebanyak 89 responden $(25 \%)$.

Dari hasil penelitian, teori dan peneliti terkait maka peneliti berasumsi bahwa seseorang yang mengalami stress itu belum mengetahui akan penyakit yang diderita hal ini disebabkan oleh tingkat pemahaman tentang penyakit, sehingga orang yang menderita penyakit menjadi takut dan sehingga timbulnya stress. 
Analisis Bivariat

Hubungan Tingkat Stress dengan Kadar Gula Darah pada Pasien Diabetes Mellitus di Poli Penyakit Dalam Rumah Sakit Bhayangkara Palembang Tahun 2019

Berdasarkan hasil uji statistik yang menggunakan Uji Chi-Square diperoleh hasil $p$ value $=0,034<(\alpha=0,05)$ Maka disimpulkan bahwa ada hubungan tingkat stress dengan kadar gula darah pada pasien Diabetes Melitus di Poli Penyakit Dalam Rumah Sakit Bhayangkara Palembang Tahun 2019.

Stress merupakan suatu respon alami dari tubuh kita ketika mengalami tekanan dari lingkungan. Dampak dari stress beraneka ragam, dapat mempengaruhi kesehatan mental maupun fisik Salah satu dampak dari stress terhadap kesehatan adalah kadar gula darah ( Endro, 2016).

Penelitian ini sejalan dengan penelitian yang dilakukan Bedjo (2015) Penelitian ini yang menyatakan bahwa diperoleh hasil $p$ value $=0,002<(\alpha=$ $0,05)$ disimpulkan bahwa ada hubungan tingkat stress dengan kadar gula darah penderita Diabetes Melitus.

Dari hasil penelitian, teori dan peneliti terkait, maka peneliti berasumsi bahwa semakin tinggi tingkat stress seseorang maka makin tinggi pula kadar gula darah seseorang, sebaliknya semakin rendah tingkat stress seseorang maka semakin rendah pula kadar gula darahnya, hal tersebut dikarenakan pada orang stress terjadi pengaktifan sistem saraf simpatis dan menyebabkan berbagai perubahan yang terjadi dalam tubuh, salah satunya adalah terjadinya proses glukoneogenesis yaitu pemecahan glukogen menjadi glukosa ke dalam darah, sehingga glukosa darah meningkat pada orang yang normal hal itu tidak menjadi masalah, namun bagi orang yang sudah menderita penyakit Diabetes Melitus tentu akan menimbulkan dampak yang kurang baik, yang dapat meningkatkan kadar gula darah, sehingga dapat menganggu kesehatan lebih komplek.

\section{SIMPULAN DAN SARAN Simpulan}

Berdasarkan hasil penelitian tentang hubungan tingkat stress dengan kadar gula darah pada pasien Diabetes Mellitus di Poli Penyakit Dalam Rumah Sakit Bhayangkara Palembang Tahun 2019, terhadap 85 orang responden didapatkan:

1. Distribusi frekuensi responden berdasarkan tingkat stres pada pasien Diabetes Mellitus di Poli Penyakit Dalam Rumah Sakit Bhayangkara Palembang Tahun 2019 bahwa tingkat stress pada pasien Diabetes Melitus yang stres ringan sebanyak 43 responden $(50,6 \%)$.

2. Distribusi frekuensi kadar gula darah pada pasien Diabetes Mellitus di Poli Penyakit Dalam Rumah Sakit Bhayangkara Palembang Tahun 2019 didapatkan bahwa pasien dengan kadar gula darah tidak terkontrol sebanyak 45 responden $(52,9 \%)$.

3. Ada hubungan tingkat stress dengan kadar gula darah pada pasien diabetes mellitus $\rho$ value $=0.034<0,05$.

\section{Saran}

Dari simpulan diatas, peneliti menyarankan sebagai berikut:

\section{Bagi Rumah Sakit Bhayangkara Palembang}

Pelayanan kesehatan terhadap penderita Diabetes Melitus di Rumah Sakit Bhayangkara Palembang sudah baik, namun harus lebih ditingkatkan lagi pendidikan kesehatan atau penyuluhan tentang Diabetes Melitus, agar dapat mengurangi stress pada penderita Diabetes Melitus sehingga kadar gula darah dapat terkontrol.

\section{Bagi Peneliti Selanjutnya}


Dapat memberikan informasi bagi peneliti selanjutnya, yang dapat melanjutkan penelitian dengan menggunakan desain penelitian kualitatif, untuk mendapatkan informasi yang lebih mendalam tentang hubungan tingkat stress dengan kadar gula darah pada pasien Diabetes Mellitus.

\section{DAFTAR PUSTAKA}

Bedjo, 2014. Hubungan Antara Tingkat Stress dengan Peningkatan Kadar Glukosa Darah Pasien Diabetes Mellitus Tipe 2 di Paguyuban Era Gendis Sehat Kabupaten Tuban

Derek dkk,2017. Hubungan Tingkat Stress dengan Kadar Gula Darah pada Pasien Diabetes Melitus Tipe II di Rumah Sakit Pancaran Kasih GMIM Manado (diakses pada tanggal 11/4/2019).

Dinkes Sumsel. 2017. Profil Kesehatan Sumatera Selatan.

Dinkes Kota. 2018. Profil Kesehatan Palembang.

Izzati, W \& Nirmala, 2015. Hubungan Tingkat Stress dengan Peningkatan
Kadar Gula Darah pada Pasien Diabetes Melitus di Wilayah Kerja Puskesmas Perkotaan Rasimah Ahmad Bukittinggi Tahun 2015 (diakses tanggal 11/4/2019).

Jamaluddin, M. (2012). Strategi Coping Stres Penderita Diabetes Mellitus dengan Self Monitoring sebagai Variabel Mediasi. 1-19.

Notoatmodjo, S. 2012. Metodologi Penelitian Kesehatan. Jakarta: Rineka Cipta

Nursalam. (2016). Konsep dan Penerapan Metodologi Penelitian Ilmu Keperawatan. (volume 2). Jakarta. Salemba Medika.

Riskesdas. 2018. Riset Kesehatan Dasar (RISKESDAS).

Waspadji, dkk. 2013. Ende Diabetes Study: Diabetes and its Characteristics in Rural Area of East Nusa Tenggara. Medical Journal of Indonesia, Vol 22, No 1 diakses tanggal 27 maret 2015 dari http: //mji.ui.ac.id/ journal /index.php/ mji/rt/ printerFriendly/ 517/ 0 